\title{
Educación indígena en la ciudad: recuento de migraciones, asentamientos y exclusión educativa en una zona periurbana de la ciudad de Puebla
}

\section{Indigenous education in the city: count of migration, settlement and educational exclusion in a peri-urban area of the city of Puebla}

Martha Josefina Franco García*

\begin{abstract}
RESUMEN
En este estudio hacemos una revisión del origen de las escuelas de Educación Indígena (El) ubicadas en la Ciudad de Puebla y analizamos las actividades escolares que realizan los niños indígenas migrantes que asisten a ellas. La investigación se sitúa en la zona nororiente de Puebla, capital. De manera específica nos abocamos a tres instituciones educativas, identificando que, a pesar de asumirse como bilingües e interculturales, no trabajan con proyectos educativos pertinentes para la atención de los hijos de familias indígenas migrantes; más aún, encontramos que estas escuelas reproducen, paradójicamente, actos de segregación y de integración, a pesar de los planteamientos internacionales y nacionales existentes en el ámbito del Derecho a la Educación (DE), en torno a la eliminación de exclusiones en las instituciones educativas.
\end{abstract}

Palabras clave: migración, periurbano, educación indígena, derecho a la educación

\section{ABSTRACT}

This article pretends to review the origin of indigenous elementary schools in the city of Puebla; and at the same time, this document analyzes all the different activities that migrant children realized in these schools. The research was realized in the north-west zone in the capital city of Puebla state. The schools for the study were selected because in these elementary schools, instead of being reorganized like bilingual and intercultural schools, we could recognize different educative practices associated to two dimensions: first, the segregation; and second, integration. This phenomenon presents a reality that is contradictory to the national and international compromises established with the Education Rights (ER). In other words, the ER are not assumed by the teachers of these elementary, bilingual and intercultural schools in the city of Puebla.

Key words: migration, peri-urban, indigenous education, right for education

\section{INTRODUCCIÓN}

En México, la atención educativa para niños indígenas ha sido una tarea marginal en las políticas educativas. Y es que desde su inicio, en 1964, la conformación del Servicio Nacional de Pro-

\footnotetext{
* Profesora de la UPN-211, Puebla; marthafrancog@hotmail.com
} 
motores Culturales y Maestros Bilingües (ahora Dirección General de Educación Indígena) fue una estructura desarticulada del sistema educativo nacional. ${ }^{1} Y$ como herencia del permanente proceso de marginación de esta modalidad educativa, su crecimiento paulatino se ha realizado de manera desordenada, operando con planes y programas generales de educación básica, ante la falta de un currículo propio.

Así, de manera segregada, sin apoyo profesional y en las condiciones más empobrecidas, fue creciendo Educación Indígena (EI), carente, en su origen, de los fundamentos psico-pedagógicos, socio-culturales y políticos acordes con las necesidades educativas de la población indígena que habita en sus regiones y la que, de manera procesual, ha migrado a las zonas urbanas, cuestión esta última de interés en este estudio.

Un elemento que muestra la condición de desventaja que tiene EI es la formación de sus profesores (Bertely, 1998; López Marcos, 2005; von Groll, Keyser y Silva, 2013), ya que estos se inician en la docencia sin una preparación académica adecuada, con un curso de inducción a la docencia y en el servicio intentan profesionalizarse ${ }^{2}$ recordando con esto los cánones de la ya histórica formación de los profesores rurales ( $c f r$. Ornelas, 1995), sin lograr, en la mayoría de los casos, la preparación pertinente, pues se observa que carecen de los conocimientos psicopedagógicos,

\footnotetext{
${ }^{1}$ Podemos considerar como antecedente del Servicio Nacional de Promotores Culturales y Maestros Bilingües, el Programa de Capacitación de Promotores Culturales del Instituto Nacional Indigenista, dirigido a jóvenes de comunidades indígenas, con la intención de que intervinieran en sus comunidades en el periodo de 1951-1962. Y, efectivamente, el proyecto de 1964 logra conformar, con el tiempo, una estructura educativa importante (una Dirección de Educación Indígena con un contingente amplio de profesores con diversas categorías, infraestructura, la creación de materiales didácticos -algunos libros de texto en diversas lenguas indígenas- y la conformación de fundamentos pedagógicos que han sustentado de manera reciente a esta educación: "bilingüe", posteriormente "bilingüe y bicultural" y en la actualidad "intercultural bilingüe". Sin embargo, estos modelos educativos no han sido resultado de un proyecto derivado de la compleja realidad étnica del país; más bien se han generado por la influencia de los discursos sobre muticulturalismo, diversidad e intercuturalidad europeos y latinoamericanos (Dietz y Mateos, 2011).

${ }^{2}$ Estos profesores se inscribían a cursos de nivelación pedagógica pues, inicialmente, contaban con la primaria o secundaria terminada; posteriormente, con bachillerato, por lo que seguían estudiando para certificarse. Fue hasta 1990 cuando la Universidad Pedagógica Nacional (UPN) inicia la profesionalización de los docentes indígenas, ofreciendo la Licenciatura en educación preescolar y primaria para el medio indígena (LEPEPMI); de esta manera, los profesores indígenas, estando en servicio, estudiaban en la UPN. Fue hasta 2010 cuando el estado de Puebla exigió que los aspirantes a una plaza de profesor de EI, fueran pasantes de la LEPEPMI y, en 2014, se les pidió también que fueran titulados.
} 
culturales y socio-lingüísticos necesarios para trabajar en el contexto indígena que implica una formación docente sólida:

La educación bilingüe intercultural implica el dominio de, por lo menos, dos lenguas (indígena y español) y el conocimiento amplio de la cultura de los sujetos que hablan estas lenguas; cuestión que no se supera con la simple ubicación lingüística de los docentes, ni la toma de conciencia, el convencimiento e interés de los mismos, sino que implica apropiarse del conocimiento epistemológico sociológico, psicológico, pedagógico y didáctico amplio y profundo que haga posible desarrollar una praxis diferente y articulada con la realidad (Hernández, citado en von Groll, Keyser y Silva, 2013).

La deficiente formación de los docentes indígenas ha sido uno de los factores que, junto con la inequidad, propicia que en EI se registre un alto índice de rezago educativo (Yonker y Schmelkes, 2005), incluso mayor que el de las escuelas rurales que atienden a población indígena (INEE, 2007).

Este marco nos da la pauta para plantear cómo ha sido la creación de escuelas de educación indígena en la ciudad de Puebla, las cuales siguen, en su conformación, la misma práctica de improvisación que caracteriza a este sistema educativo, debido a que no se les posicionó desde su diferencia dentro del proyecto educativo de la entidad; más bien, se les incluyó de manera marginal, sin mediar un sustento pedagógico y político que las justifique como proyecto alternativo; sin un currículo que aborde los procesos de desplazamiento y asentamiento de poblaciones campesinas e indígenas ${ }^{3}$ en las zonas metropolitanas; y sin una propuesta de trabajo sociolingüística para las actividades escolares (Franco, 2013).

\footnotetext{
${ }^{3}$ En este trabajo hacemos una distinción entre campesino e indígena. Nos referimos a los campesinos como los sujetos que viven en la zona rural y se relacionan, en mayor o en menor medida, con actividades agrícolas o ganaderas. Por el tema aquí planteado, hacemos referencia al pequeño y mediano productor agrícola que, a consecuencia de la globalización y las políticas de liberación económica que han transformado el campo mexicano, se han visto obligados a incrementar la emigración y el multiempleo en el ámbito rural (Rello y Saavedra, 2012). Y consideramos a los indígenas como los sujetos que asumen una pertenencia étnica (Bartolomé, 2004). Podemos considerar que los pueblos indígenas están situados en la zona rural y los indígenas, generalmente, son campesinos que también sufren las condiciones antes señaladas.
} 
No obstante, en la actualidad es un imperativo el trabajo especializado para atender a población migrante indígena que habita en las ciudades. En este sentido, nos acercamos a la realidad sociohistórica de estas escuelas para documentar sus procesos como instituciones escolares encargadas de trabajar con niñas y niños indígenas y mestizos.

Para ello, realizamos este estudio desde una perspectiva cualitativa. ${ }^{4}$ Consideramos relevante elucidar la construcción de sentido que los propios actores dan del hecho social, tomando en cuenta el contexto sociohistórico en que están inscritos (Castoriadis, 1989).

Reconocemos que "la investigación cualitativa es un modo inductivo de encarar el mundo empírico"s (Taylor y Bogdan, 1990: 20), el trabajo atento, cara a cara, nos permitió el reconocimiento comprensivo de las prácticas discursivas de los actores sociales en torno al hecho de indagación. De esta manera, tanto las observaciones como las entrevistas a los estudiantes, maestros, directivos, padres de familia y colonos, generaron datos descriptivos cada vez más ricos que nos permitieron "desarrollar intelecciones y comprensiones" (Schutz y Luckman, 2009). Para ello también nos apoyamos en herramientas teóricas y material documental.

El estudio se centró en tres escuelas primarias de EI: Fuertes de Guadalupe y Loreto, Tierra y Libertad y Emiliano Zapata. ${ }^{6}$ Realizamos el trabajo de reconstrucción histórica y contextual a través de entrevistas a profundidad a una profesora fundadora de EI en la ciudad de Puebla; a tres docentes con más de veinte ańos de servicio en las escuelas en que realizamos la investigación, y a dos colonos que fueron padres de familia cuando se construyeron las escuelas.

\footnotetext{
4 "Maxwell (citado en Vasilachis, 2006: 26) señala que, entre los rasgos más característicos de la investigación cualitativa, se encuentran: a) el interés por el significado y la interpretación, b) el énfasis sobre la importancia del contexto y de los procesos, y c) la estrategia inductiva y hermenéutica". En este sentido, el eje de nuestra investigación fue la comprensión del fenómeno educativo, con el interés de lograr su interpretación (Piña, 1998; Woods, 1998; Taylor y Bogdan, 1990).

${ }^{5}$ El método inductivo parte de la condición de "obtener principios explicativos a partir de los fenómenos que se han de explicar” (Mardones, 1983: 17).

${ }^{6}$ Precisamente, para este estudio, escogimos las dos primeras escuelas primarias de educación indígena que se fundaron en la zona escolar 113 (Fuertes de Guadalupe y Loreto y Emiliano Zapata); y la tercera escuela, Tierra y Libertad, es el turno vespertino de la última.
} 
Para conocer datos cuantitativos y cualitativos de los niños migrantes e indígenas en estos centros educativos, realizamos entrevistas a profundidad a los tres directores de estas escuelas y a los tres maestros antes mencionados; además, efectuamos observaciones no participantes en las tres instituciones educativas (para cada una elaboramos dos registros de observación).

La estructura del trabajo consiste en dos apartados; el primero, constituye una revisión de estudios sobre migración del campo a la ciudad y, de manera específica, la migración indígena, con la finalidad de contextualizar la presencia de los niños indígenas migrantes en espacios periurbanos, lo que nos permitió elucidar la situación en que se inscriben a la escuela. La segunda parte es una descripción del origen de la EI en la ciudad de Puebla y el análisis desde el Derecho a la Educación (DE), de las condiciones de escolarización de estos estudiantes.

\section{MIGRACIÓN DEL CAMPO A LA CIUDAD: EL CASO DE PUEBLA}

El desplazamiento que realiza la mayoría de los campesinos e indígenas de sus comunidades de origen hacia las ciudades tiene como motivo principal obtener un empleo que permita la subsistencia y el acceso a servicios de los cuales carecen. En la diáspora, estos sujetos se inscriben en relaciones de poder (económicos y sociales) profundamente asimétricos, convirtiéndose en mano de obra de reserva, precarizada, barata, disponible, flexible y no especializada para la manufactura y los servicios fuera de sus comunidades de origen.

$\mathrm{Y}$ es que, de acuerdo con Bauman, "los procesos globalizadores que vivimos incluyen una segregación, separación y marginación social progresiva" (2006: 9), con lo que se dinamizan los desplazamientos en busca de oportunidades que, para los más pobres, se ofrecen en las condiciones más exiguas e inciertas. De esta manera, se mantienen en los socavones sociales, pero ahora en espacios más adversos, debido a que se sitúan en sitios desconocidos y sin seguridad en el empleo y la vivienda.

Encontramos antecedentes sobre estudios de migración del campo a la ciudad en los trabajos de Arizpe que refieren a que, en la década de los setenta, "la migración rural-urbana a gran escala, 
era resultado, en primera instancia, de una transformación económica estructural, y que influyen en su selectividad y formas de migrar factores tales como la organización social comunitaria y familiar, las tradiciones y los cambios culturales" (1978: 248). De esta manera, se articulan los factores externos a las condiciones propias de familias y pueblos.

El efecto demográfico en torno a la migración rural nos muestra cómo se ha transformado la zona rural de baja agricultura y cómo, en un principio, las ciudades y, posteriormente, sus zonas conurbadas, fueron recibiendo a esta población, hasta llegar a nuevas condiciones de vida en espacios que podemos considerar como rural-urbanos, donde se ha modificado el uso y formas de habitarlo.

De Grammont refiere que, "en 1921 la población rural representaba $68 \%$ de la población total y actualmente se acerca a solo $25 \%$. Durante estos años, México pasó de ser un país agrario a uno urbano" (2005: 11-12), debido al flujo migratorio del campo a la ciudad. Este desplazamiento fue conformando realidades diversas, novedosas, complejas, pero también, de transposición de patrones de vida.

El mismo autor advierte que debemos distinguir dos etapas en la conformación de la urbanización del país; "la primera, que corresponde al proceso de industrialización hacia adentro y al desarrollo estabilizador; la segunda, que comprende la globalización y la apertura comercial" (ibid.). En el primer momento, de $1950^{7}$ a 1970 se observó una migración del campo a la ciudad que tendió a consolidar asentamientos definitivos. ${ }^{8}$

En el tenor de este desarrollo estabilizador, que ponía como centro a la industrialización y se consolidaba en contados polos de desarrollo, se mantuvieron los subsecuentes gobiernos. En esta

\footnotetext{
${ }^{7}$ Por su parte, Arias (2002) y, más tarde, Olvera (2013), refieren que, desde la década de los cuarenta, se inicia la migración hacia las ciudades. "El auge del desarrollo industrial, que catapultó a los principales centros económicos del país, a la vez que se dio la paulatina desinversión en el sector agrícola, principalmente en las regiones centro y sur de la República, fraguando con ello desarrollos desiguales entre regiones" (Olvera, 2013: 37).

${ }^{8}$ Lazarín (1996: 167) refiere que con Ávila Camacho (1940-1946), Alemán (1946-1952) y Ruiz Cortines (1952-1958) se impulsó una política nacional que pretendía industrializar al país, aprovechando la escasez - provocada por la guerra- de productos manufacturados extranjeros. Esta carencia propició reformular el rumbo económico y productivo de la Nación y, de esta manera, se impulsó el éxodo del campo a la ciudad.
} 
etapa, se observó un gran desplazamiento del campo a la ciudad y los inmigrantes tendieron a establecerse de manera definitiva en las ciudades de arribo.

Posteriormente, en la segunda etapa, que se advierte desde la década de los ochenta se observa otra directriz, producto de la globalización. Esto se patentiza de manera contundente una década después. "A partir de los años noventa, con la inclusión de México en el TLCAN (1994) y la adopción de la economía de libre mercado, cambiando las reglas de juego en la producción y comercialización de bienes" (Olvera, 2013: 38).

Con ello se da paso a la libre economía que plantea, entre sus diferentes pautas, fuentes de trabajo precarias y transitorias. Estas condiciones de vida inciertas (donde el trabajo flexible e inestable es el patrón generalizado) dificultan que los inmigrantes se establezcan de manera definitiva. A su vez, las nuevas características laborales dan paso a las migraciones temporales, de larga duración e incluso diversificadas.

La migración actual tiene como sedimento la primera etapa, la del crecimiento hacia adentro, que vislumbraba una modernización que consolida la estructura urbana e instaura una sensación de inclusión del inmigrante rural. Al agotarse esta posibilidad, la reciente inmigración se inscribe en una realidad donde lo incierto prevalece como porvenir y el retorno hacia la comunidad de origen es probable, lo mismo que migrar hacia un nuevo enclave que les ofrezca mayores oportunidades laborales. A pesar de esta diferenciación, la primera etapa no rompe con la segunda, e incluso se instaura la segunda en los cimientos económicos, sociales y simbólicos de la primera.

Los migrantes llegan, generalmente, a zonas periurbanas ${ }^{9}$ (espacios rurales limítrofes a las ciudades), donde se asienta población que se inserta a la dinámica urbana, y donde se constituyen, de manera compleja, entre tensiones y contradicciones, interacciones novedosas producto de la reconstitución espacial

\footnotetext{
${ }^{9} \mathrm{El}$ concepto periurbano se utiliza para hacer referencia tanto a un espacio geográfico, como a los procesos sociales que ocurren en él. Desde una perspectiva geográfica, lo periurbano puede manifestarse territorialmente, en el caso de las grandes ciudades y conglomerados urbanos, en la conformación de coronas o espacios periféricos concéntricos entre los que permanecen intersticios rurales... los espacios periurbanos presentan dinámicas complejas y conflictivas ante los cambios sociales, económicos y culturales que ocurren en los asentamientos rurales, al integrarse a la ciudad (Calderón y Soto, 2014: 126).
} 
y social. En esta realidad se articulan, de forma importante, el espacio geográfico y la vida social.

En las zonas periurbanas las experiencias colectivas son múltiples y, con ello, entre encuentros y encontronazos, se fragua el día a día. En estos espacios, que tienen historia, se mantienen ciertos rasgos sociales ancestrales, a pesar de las transformaciones de las que son objeto al desplazar su vocación campesina a la utilización habitacional. ${ }^{10}$

Existen problemas sociales, ${ }^{11}$ producto de la relación entre los pobladores originarios y los que han llegado, como la lucha frontal por la acreditación de asentamientos que, en su origen, fueron irregulares o litigios por la propiedad de la tierra; así también densidad de población, carencia de servicios, marginación; pero también un encuentro multiétnico, que tiene como sustento social importantes rasgos culturales étnicos que se incorporan al tejido social. Todas estas características sociales se advierten en la zona donde están ubicadas las tres escuelas de EI de nuestro estudio.

En el nuevo lugar de asentamiento los inmigrantes viven procesos sociales complejos, donde las prácticas cotidianas han consolidado estilos de vida periurbanos, propios de la condición específica del lugar de referencia, que se configura a partir de articular-dificilmente- lo social y lo étnico. ${ }^{12}$

El conocimiento detallado de lo que sucede en la parte exterior a los límites de la ciudad, es decir, lo periurbano y lo rururbano, tiene mayor importancia en la medida en que ahí hay una mayoría

\footnotetext{
10 "Durand, en 1983, mostró que la expansión de la urbanización popular se había topado con espacios vividos, es decir, con territorios donde había gente con historia y trayectoria como los campesinos del pueblo de San Bernabé... El estudio dejó al descubierto una posibilidad: la complejidad del proceso de expansión y poblamiento de espacios periféricos que desde la perspectiva de los inmigrantes podían verse vacíos, no así desde las comunidades a las que les había llegado, como caída del cielo o del infierno, la demanda urbana de nuevos usos del suelo, de su suelo" (Arias, 2002: 366, 367). El espacio agrícola sufrió transformaciones de gran envergadura y con esto sus pobladores se vieron sometidos a prácticas instauradas por la dinámica urbana, pero también mantuvieron ciertas prácticas locales, que marcan lo que en la actualidad se vive en ellos.

${ }_{11}$ Mientras, en las comunidades expulsoras se manifiestan procesos de despoblamiento-repoblamiento, dependencia económica del exterior, diversificación de actividades agrícolas y de servicios, esta última con mayor alcance, entre otros fenómenos que impactan la estructura social y económica y, de manera importante, la subjetividad.

${ }^{12}$ Por las características de nuestro país, el desplazamiento del campo a la ciudad concentra una diversidad étnica importante. Esto debiera tomarse en cuenta cuando se diseñan las políticas públicas en materia de salud, educación, urbanización, etcétera.
} 
de población diferente de la que habita dentro de los límites tradicionalmente reconocidos de la ciudad (Ávila, 2005: 37).

De esta manera, el factor étnico, en vinculación con la clase social, constituyen ejes ordenadores en las relaciones que se construyen en torno a la habitabilidad, aprendiendo desde esta experiencia social "a vivir juntos" (Touraine, 1997), a pesar de las tensiones y contradicciones propias de la relación, en sitios minados por la condición de segregación, única forma en la que han podido insertarse los migrantes a la ciudad (cfr. Arias, 2002).

"Los espacios periurbanos día con día se nutren de gente y actividades que, con su devenir cotidiano, están construyendo formas de relación, espacios de convivencia, maneras de ganarse la vida y culturas laborales distintas" (ibid.: 378) construidas desde relaciones locales y de movilidad, inscritas en dinámicas globales; por ello lo inédito de su conformación.

De manera concreta, nuestro interés por dar cuenta de la noción de espacios periurbanos se debe a que las escuelas de educación indígena en Puebla, capital, se ubican en este tipo de lugares; por ello, nos permite situar a los sujetos no solo desde lo geográfico, sino también desde su historia, su configuración y su reconfiguración social (al ser interpelados por instituciones como la educativa).

Con respecto a la migración interna poblana, INEGI (2005) refiere que los municipios mayoritariamente receptores de población en el estado de Puebla son: Puebla, capital, con $46.6 \%$ y otros 13 municipios, que recibieron $28.4 \%$ del resto de inmigrantes, según el censo de 2000. En 2010, el porcentaje de población no nativa (migración acumulada) en la ciudad es de 9.20\% (INEGI, 2010).

En la periferia del municipio de Puebla (sitio con el mayor volumen de migración) resaltan, por su importancia, los asentamientos situados alrededor de la Central de Abastos y el corredor industrial, lugares que inician su poblamiento de forma posterior a la instalación de estos espacios laborales. Precisamente en este sitio, Martínez (2008) realizó un estudio sobre educación con la población migrante que se instala en la colonia Tres Cerritos; por su parte, Bello (2004) se acerca a revisar la realidad educativa en Barranca Honda. En ambos trabajos se identifica la diversidad étnica de los residentes y sus procesos de formación escolarizada. 
A su vez, Gómez y sus colaboradores (2007) identifican las relaciones de género en una zona periurbana al Sur de la ciudad de Puebla. En este espacio, la población tiene una trayectoria migratoria del campo a la ciudad y recientemente se ha articulado también a la migración internacional. Este sitio, una colonia creada y sostenida por un movimiento popular, apéndice del Partido de la Revolución Institucional (PRI), Antorcha Campesina, ${ }^{13}$ se mantiene con población flotante y una estructura poblacional diversa.

También encontramos que, de manera reciente, ha inmigrado población a la Junta Auxiliar de San Francisco Teotimehuacan, lugar de origen náhuat ${ }^{14}$ del municipio de Puebla, que ha lotificado gran parte de su tierra agrícola para venderla a precios muy baratos, como terreno rústico. Portillo $(\mathrm{s} / \mathrm{f})$ señala que en esta junta auxiliar, en las faldas del cerro -el lugar más apartado-, se creó la colonia Santa Catarina y a este lugar han llegado a vivir personas de poblados cercanos como Santo Tomás Chiautla, Lomas de San Miguel y Zaragoza, además de población indígena (totonacos, mixtecos y popolocas) de la entidad poblana y mazatecos del estado de Oaxaca. ${ }^{15}$ Esta diversidad étnica, refiere Portillo (s/f), se advierte y complejiza en las instituciones educativas del lugar.

En La Resurrección ${ }^{16}$ también se conformaron asentamientos irregulares en espacios destinados, originalmente, a reservas territoriales y tierras ejidales, lo que cambió el uso territorial y creó

\footnotetext{
${ }^{13}$ Antorcha Campesina es una organización social originaria del estado de Puebla y actualmente tiene presencia nacional. Surge en la década de los setenta y su incidencia es en el ámbito rural y en colonias populares. Su lema es "Organización de los pobres de México" y políticamente se ha articulado con el PRI.

${ }^{14}$ La población originaria de San Francisco Teotimehuacan mantiene usos y costumbres indígenas; incluso todavía algunos adultos hablan náhuatl y algunos jóvenes mantienen diversos grados de bilingüismo (español-náhuatl).

${ }^{15} \mathrm{El}$ sostenimiento de estas familias inmigrantes es el trabajo de los padres que laboran en seguridad pública (policías auxiliares, municipales, estatales o custodios, en industrias, como empleadas domésticas y en el comercio informal). Este espacio ha sido modificado para uso habitacional no planeado y su dinámica actual es de recepción de población rural que tiende a adaptarse a las condiciones de carencia del sitio. Lo interesante es que existe un fuerte componente étnico diverso que, circunstancialmente, ha llegado a recrear el entorno social.

${ }^{16}$ La Resurrección, en otro tiempo, fue un municipio libre y soberano; sin embargo, por decreto de anexión, promulgado por el XLI Congreso del Estado de Puebla, el 30 de octubre de 1962, se constituyó como junta auxiliar de la ciudad de Puebla (INAFED, s/f); con ello, en la actualidad, junto con otros cinco exmunicipios, forma parte del territorio ampliado de Puebla, capital. Este sitio, que en otro tiempo fuera eminentemente rural, formó poblados en asentamientos irregulares que hoy son colonias populares como Manzanilla, Tilostoc, Santa Anita, Nueva Resurrección y San Antonio Abad. En estos sitios encontramos inmigrantes llegados tanto del interior del estado como de otras entidades federativas.
} 
colonias periféricas, como parte del crecimiento de la mancha urbana. Estos asentamientos se caracterizan por haber carecido, en su origen, de servicios; de manera lenta se les fue dotando de agua, drenaje, pavimentación, escuelas y servicios de salud, debido a que por mucho tiempo no estuvieron regularizados en el catastro o por estar consideradas como zonas de riesgo. ${ }^{17}$

En este espacio, Franco (2013) realiza un acercamiento a la formación y operación de escuelas de educación indígena, señalando las condiciones en que han funcionado desde su origen, con énfasis en la marginación de que son objeto. En esta región se ubican cuatro primarias y tres preescolares de educación indígena $\mathrm{y}$ es precisamente en tres de ellas donde realizamos este estudio.

Creemos que en la revisión que hemos presentado, el componente étnico juega un papel importante, sobre todo en su recurrencia y en la manera en que los individuos y las familias migrantes se inscriben a las zonas periurbanas de la metrópoli poblana y las y los niños a "las escuelas del rumbo"; por este motivo, a continuación hacemos referencia a la migración indígena.

En la migración poblana encontramos el componente étnico de manera relevante; por ello nos interesa realizar una revisión del comportamiento de la migración indígena en la entidad. Esta ha seguido un patrón: la preferencia por la migración intrarregional; y a medida que la salida implica un desplazamiento mayor, el número de migrantes disminuye (INEGI, 2005). Sin embargo, actualmente, aunado a este patrón, encontramos desplazamientos múltiples e incluso novedosos, producto de la necesidad de empleo; los requerimientos de la economía nacional y mundial, y las formas de subsistencia tradicionales que nos están planteando movilidades unidireccionales, pendulares, de retorno y escalonadas, tanto en el territorio estatal como en el nacional y, en algunos casos, de esta se encadena la internacional (Gómez et al., 2007) o primero la interna -estatal y nacional-y posteriormente la internacional (Rivermar, 2008; D’Aubeterre y Rivermar, 2014).

\footnotetext{
${ }^{17}$ En dichos lugares es práctica común que los líderes de los colonos organicen a la población para presionar a las autoridades o para afiliarse a partidos políticos con la finalidad de ir regularizando los predios y acceder a los servicios básicos, a pesar de que algunas de las colonias se sitúen en zonas peligrosas que, indebidamente, se ocupan para edificar viviendas.
} 
El INEGI plantea que, al revisar los índices de migración, en relación con la condición hablante de lengua indígena, existe, al parecer, una evidente dificultad de desplazamiento para los indígenas. ${ }^{18}$

El ser hablante de lengua indígena limita las posibilidades de movimiento territorial con fines de cambio de residencia, no solo por las dificultades de comunicación e integración, aunque la mayoría de los hablantes son bilingües, sino que también es importante el arraigo de esta población a los territorios de los cuales son nativos, fomentado por la organización comunitaria prevaleciente en ello (INEGI, 2005).

No obstante, en las comunidades indígenas es posible observar procesos de migración de alguno o algunos de los miembros de las familias extensas que salen para contribuir con la manutención del hogar. Según datos del INEGI, en la entidad poblana se observa que "entre quienes llegaron o se fueron de la entidad, el porcentaje de hablantes de lengua indígena es similar. Con 7.2\% los primeros y 8.3\% los segundos" (INEGI, 2005). Con estos datos, en principio, podemos observar que sí existe una dinámica migratoria de indígenas (de salida y retorno); esto, además, muestra el vínculo que se tiene con el lugar de origen -el retorno- y la posibilidad de tender redes migratorias que edifican espacios para que transiten otros.

Cuando se consolidan las redes migratorias es posible identificar, en el lugar de arribo, espacios etnizados, ${ }^{19}$ que tienden a reproducir las prácticas sociales de los inmigrantes y, a la larga, a conformar núcleos familiares donde se constituye la segunda generación. En estas circunstancias, es posible permanecer fuera de la comunidad de origen, pues en la diáspora se va construyendo una forma de pertenencia donde la identidad étnica ${ }^{20}$ se cons-

\footnotetext{
${ }^{18}$ El INEGI considera a los indígenas a partir de 5 años en adelante y hablantes de su lengua materna; sin embargo, un número importante de indígenas son bilingües o incluso tienen grados diversos de apropiación de su lengua materna o la han perdido.

${ }^{19}$ Hacemos referencia a los espacios etnizados como los lugares (barrios, colonias o comunidades) habitados por población indígena migrante u oriunda que tiende a recrear prácticas sociales étnicas impactando culturalmente dicho espacio social.

${ }^{20}$ Bartolomé (2004: 76) plantea que la identidad étnica no es esencial, sino cambiante; de esta manera, apunta que se "refiere al estado contemporáneo de una tradición, aunque puede desarrollar una imagen ideologizada de sí misma y de su pasado como forma de recons-
} 
truye y reconstruye; y en estas prácticas culturales, los migrantes reinterpretan sus experiencias de vida a la luz de su propia cosmovisión (Rivermar, 2008).

Bartolomé (2008) advierte un juego entre la reformulación identitaria y los rasgos sedimentados que posibilitan la distintividad. Para Bhabha, la relación con la otredad crea escisiones y con ello un imposible retorno al origen. La experiencia con el otro trastoca los referentes ya construidos.

La demanda de identificación (esto es, ser para un Otro) implica la representación del sujeto en el orden diferenciante de la otredad. La identificación siempre es el retorno de una imagen de identidad que lleva la marca de la escisión en el Otro lugar del que proviene (Bhabha, 2002: 66).

$\mathrm{Y}$ en este proceso, lo indígena visto por los otros suele tener visos no solo culturales (por sus creencias y prácticas), sino también, y de manera contundente, de extraños. ${ }^{21}$ En este caso, desde la perspectiva de los otros, en la construcción identitaria (Barth, 1976; Dubar, 2002; Bartolomé, 2004; Giménez, 2007; Chávez, 2014) su identidad se ve trastocada por relaciones de discriminación y exclusión (Chávez, 2014), lo que va a mediar, irremediablemente, en la propia construcción étnica del grupo y de las nuevas generaciones. Esto debido a que en la conformación de las identidades étnicas desde "los otros" -los mestizos- el referente eurocéntrico es un marcador que posiciona hacia abajo lo indígena.

trucción afirmativa". Señala también que existen evidentes transformaciones que registran las identidades étnicas a través de la historia, redefiniéndose la frontera que nos diferencia de los otros a través del tiempo. Por su parte, Rivermar señala que, en la actualidad, la identidad étnica en situaciones de migración, se reorganiza en el contexto de la globalización, donde la cultura tiene un papel preponderante para organizar el mundo de la vida del sujeto y de su comunidad "recuperando novedades que encuentra en los lugares adonde migra, adopción que es entendida en la medida en que mantiene núcleos fundamentales de su cosmovisión y cultura" (2008: 242). Por su parte Bartolomé refiere que: "Los migrantes étnicos no asumen nuevas identidades derivadas de las clasificaciones externas, sino nuevas representaciones de su identidad como miembros de una colectividad que se confronta con otra en un nuevo contexto... [Y a través del tiempo el contacto con los otros] propicia la reformulación identitaria manteniendo la distintividad" (2008: 59).

${ }^{21}$ Diferencias sociales que los han clasificado como otros, desde la perspectiva del grupo y/o la sociedad dominante [...] mediante la delimitación de fronteras étnicas provenientes del exterior, de discursos y acciones que los hacen sentirse ajenos a una sociedad urbana y mestiza (Chávez, 2014: 36). 
De esta manera, las relaciones sociales suelen ser conflictivas tanto por las diferencias de clase, como por las culturales: "las relaciones interétnicas son, generalmente, relaciones de clase que se expresan en una ideología y en la ubicación de ciertas posiciones sociales que orientan la experiencia de los sujetos" (Comaroff y Comaroff, citados en Chávez, 2014: 38). Se advierte una relación interétnica jerárquica medida por la etnia y la clase social (Bhabha, 2002; Krotz, 2015). Todo ello está presente en la construcción social y en las instituciones. Por ello, nos interesa reconocer, no únicamente la composición étnica de la población escolar, sino también la forma en que la escuela trabaja con las y los estudiantes indígenas migrantes en relación con la diferencia cultural mediada por la clase social.

De esta manera, tomando en cuenta la construcción social de la identidad, la experiencia de los sujetos con la otredad y el papel de la escuela como institución transmisora de un legado cultural institucionalizado, hacemos una descripción de la población indígena de las colonias Nueva Resurrección y San Antonio Abad, sitios donde se ubican las escuelas Fuertes de Guadalupe y Loreto, Emiliano Zapata y Tierra y Libertad.

Los pobladores de la colonia Nueva Resurrección tienen un origen diverso pues han llegado del interior de la entidad y de los estados de México, Veracruz y Oaxaca; otras personas son oriundas de la propia ciudad de Puebla.

Con respecto a la población indígena, allí habitan, sobre todo, nahuas y totonacas de la Sierra Nororiente y mixtecos de la región de Tepeji de Rodríguez. Esta población ha crecido debido a las redes tendidas entre la comunidad de origen y la colonia a donde llegan miembros de una familia o la familia completa; además, algunas de estas personas se han casado, han formado familias y han constituido, en la diáspora, una segunda generación.

En la colonia San Antonio Abad, también se han tendido redes de población oriunda de la Sierra Norte, la Mixteca poblana y de Oaxaca. La población indígena de esta colonia son nahuas, totonacos, mixtecos, popolocas, ñähñus, zapotecas y mazatecos.

Los nichos laborales de los inmigrantes indígenas recientes en estas colonias son, sobre todo, la albañilería, el servicio doméstico, ayudantes en los pequeños comercios, el ambulantaje, veladores 
y repartidores de tanques de gas, actividades que no requieren de una especialización, son de baja remuneración y suelen ser eventuales. ${ }^{22}$ Aunado a esto, encontramos, en la colonia San Antonio Abad, personas dedicadas a la recolección de pet, cartón y vidrio. Dadas las condiciones de precariedad, inseguridad laboral y la baja remuneración en las actividades informales que realizan los migrantes indígenas recientes, se advierte una población flotante, gente que se mantiene por largas o cortas temporadas y posteriormente regresa a su pueblo o parte otro lugar en busca de empleo. En ocasiones también se llega a observar que un miembro de la familia sale hacia Estados Unidos.

En cada caso, la conformación social se deriva tanto de las condiciones de la economía globalizada que atrae, absorbe o expulsa a los trabajadores inmigrantes que aglutina en esos espacios de "reserva", y de la condensación de prácticas y relaciones (con sus evidentes juegos de poder al interior y exterior), producto de la conformación social de sus actores. Estos factores a través del tiempo confieren un perfil propio a cada espacio.

El tejido social se inicia y anuda desde las comunidades de origen y de allí se van conformando redes con flujos variables determinadas, generalmente, por las condiciones laborales y económicas. Cada pueblo expulsor tiene una historia propia y, de esta manera, articula sus formas de producción a los ritmos y requerimientos de la economía nacional y global. Sin embargo, "por las actuales condiciones del trabajo precario y flexible, los migrantes tienen mayores dificultades para instalarse definitivamente en las regiones de atracción. Así, la combinación de la inestabilidad del trabajo, junto con la mayor competencia entre los trabajadores, crea "flujos migratorios temporales" (De Grammont, 2005: 14).

Es importante plantear que las condiciones laborales, en la actualidad, están generando desplazamientos que llevan como

\footnotetext{
${ }^{22}$ Es de señalar que los indígenas que llegaron cuando se fundaron estas colonias, lograron emplearse en la industria (como obreros o en los servicios de vigilancia y limpieza de las empresas), ya que cerca de estas colonias se encuentra un corredor industrial; otros tienen pequeños comercios. También encontramos que en estas colonias y la contigua (Manzanilla), habitan maestros indígenas jubilados y en servicio y sus hijos, algunos han conformado una familia y se han quedado a vivir en este mismo sitio. Sin embargo, los actuales migrantes indígenas difícilmente logran incrustase a estos nichos laborales.
} 
constante la incertidumbre y lo provisonal. Desde este marco donde los movimientos de personas y familias se articulan, se cruzan, son pendulares, etc., se está conformando la vida de las familias que hoy, como nunca, se mueven de forma diversa y en condiciones de gran vulnerabilidad. En esta realidad, la escuela es un espacio de encuentro entre los desplazados y la población que los ve llegar e irse.

\section{LA ESCUELA PARA NIÑOS INDÍGENAS MIGRANTES EN LA CIUDAD DE PUEBLA}

Es necesario señalar que, en el estado de Puebla, "la proporción de niños migrantes recientes de 5 a 14 años que no asisten a la escuela es de $7.4 \%$, mayor que aquellos que no cambiaron de residencia (6.4\%), (INEGI, 2012: 6). Estos datos nos muestran, primero, que no está garantizado el $\mathrm{DE}$ de todos los y las niñas y que esta exclusión es todavía mayor para los niños migrantes.

Sin dejar de señalar que lo anterior representa la mayor injusticia educativa, en este apartado nos avocamos a describir el servicio educativo que ofrece la EI en la ciudad de Puebla y, de manera puntual, en tres escuelas que se caracterizan por recibir a niños de familias migrantes indígenas y campesinas. En este caso, nuestro interés es identificar la atención educativa para las y los niños migrantes indígenas que asisten a este tipo de escuelas, teniendo presente que las acciones de atención para la población indígena y migrante es encomendada actualmente por la SEP a EI (SEP, 2012). Sin embargo, nosotros reconocemos que no todos los estudiantes indígenas migrantes asisten a esta modalidad educativa en Puebla, capital, ya que otros están inscritos en escuelas generales, sobre todo en las zonas periurbanas de la metrópoli poblana.

También nos interesa identificar las acciones educativas que brinda EI en estas escuelas desde el marco del derecho a la educación (DE); tomando en cuenta que, en la actualidad, las necesidades de aprendizaje son más complejas y deben ser atendidas por la escuela como parte fundamental de las garantías que tiene todo ser humano (Di Pierro, 2008; López Néstor, 2012). Ante esto, la escuela de hoy vive grandes retos debido a que se ha convertido 
en un espacio donde los sujetos confluyen desde construcciones familiares y sociales diversas, producto, entre otras cosas, de una movilidad sin precedentes.

La confluencia de estos estudiantes en el aula debería ser potenciadora de aprendizajes desde la diversidad y la diferencia, debido a que las múltiples experiencias permiten abrir el espectro de posibilidades de formación e interacción horizontal. En este sentido, es necesario recordar que a través de la historia del DE, se observa como refiere Tomasevski (2002), un largo proceso de superación de exclusiones que puede situarse en tres etapas fundamentales.

La primera se refiere a la concesión del DE a aquellos a los que se les ha denegado (los pueblos indígenas o los no ciudadanos). Esta etapa entrańa una segregación. Se otorga el acceso a la educación, pero se les confina a escuelas especiales. La segunda requiere abordar la segregación educativa y avanzar hacia la integración, en la que los grupos que acaban de ser admitidos tienen que adaptarse a la escolarización disponible. Los niños pertenecientes a minorías se integrarán en escuelas que imparten enseñanza en lenguas desconocidas para ellos y versiones de la historia que les niegan su propia identidad. La tercera etapa exige una adaptación de la enseñanza a la diversidad de aspectos del DE, sustituyendo el requisito previo de que los recién llegados se adapten a la escolarización disponible por la adaptación de la enseñanza al derecho igualitario de todos a la educación y a los derechos paritarios en ese ámbito (Tomasevski, 2002: 15-16).23

Sustentado en esta última etapa, el artículo $5^{\circ}$ de la Declaración Mundial sobre Educación para todos, de Jomtien, 1990, denominado "Ampliar los medios y el alcance de la educación básica", señala que "la diversidad, la complejidad y el carácter cambiante de las necesidades básicas de aprendizaje de los niños, jóvenes y adultos exigen ampliar y redefinir constantemente el alcance de la educación básica" (UNESCO, 1994) y, para ello, plantea que la educación primaria debe ser universal, garantizar la satisfacción de las necesidades básicas del aprendizaje de todos

\footnotetext{
${ }^{23}$ Las tres etapas nos muestran cómo se ha ido propiciando que el excluido, que se mira socialmente como una minoría, en este caso el inmigrante indígena, deba acceder a una educación pertinente.
} 
los niños y tener en cuenta la cultura y las necesidades de la comunidad.

En este tenor, el Programa Sectorial de Educación 20132018 apunta en el objetivo 3. Asegurar mayor cobertura, inclusión y equidad educativa entre todos los grupos de la población para la construcción de una sociedad más justa que "las escuelas e instituciones educativas deben atender las particularidades de los grupos de la población que más lo requieren. En especial, deben desplegarse estrategias que contemplen la diversidad cultural y lingüística (SEP, 2013b: 54).

En este sentido, la atención educativa para los niños indígenas y campesinos que se incorporan a las escuelas de EI en la ciudad de Puebla, debieran adaptarse a las necesidades de estos estudiantes a partir, primero, de realizar un diagnóstico para conocer la diversidad cultural y lingüística que existe en la escuela $y$ en las aulas $y$, segundo, construir proyectos educativos pertinentes, enfocados en las necesidades educativas de estos niños, tomando en cuenta sus prácticas sociales como lo refieren los Marcos Curriculares ${ }^{24}$ elaborados por EI.

Los Marcos Curriculares conciben una escuela abierta a la comunidad, que requiere de ella para definir las prácticas sociales y culturales pertinentes y con base en los saberes ancestrales y actuales; y la cultura migrante en su caso, se incluyan en la escuela, considerando una comunidad educativa que tienda redes de apoyo a la nińez para fortalecerla ante las situaciones de riesgo de exclusión (SEP, 2011: 61).

Este escenario, construido por una serie de políticas educativas dirigidas de manera fehaciente al reconocimiento a la diversidad, constituye el resultado de un largo proceso de superación de exclusiones, ${ }^{25}$ y representa el marco en que se sustenta la EI;

\footnotetext{
${ }^{24}$ Marcos Curriculares son planteamientos elaborados por la Dirección General de Educación Indígena, en los que se establecen "los fundamentos normativos, jurídicos, curriculares, socioculturales, pedagógicos, metodológicos y didácticos que permiten el desarrollo del currículo local al contextualizar y diversificar las experiencias y oportunidades de aprendizaje de las niñas y niños, desde su realidad inmediata, que le da sentido y significado al proceso de apropiación de los conocimientos de los propios pueblos originarios y culturas migrantes y de aquellos contenidos de los programas de estudio" (SEP, 2012).

${ }^{25}$ Respecto a la exclusión, Saraví (2009: 23) refiere que las situaciones más extremas de exclusión son el resultado final de proceso de acumulación de desventajas que pueden tener
} 
no obstante, surge la pregunta de si todo esto impacta, de manera adecuada, la realidad de EI en la ciudad y si con ello se incide en la equidad en un país con históricas desigualdades (INEE, 2007; Latapí, 2009). De manera puntual en ese día a día de las escuelas a las que asisten niñas y niños migrantes indígenas. Revisemos para dar cuenta de ello la estructura y origen de las escuelas de EI en la ciudad. En Puebla, capital, se ubica el sector 02 Región nahua, conformado por siete zonas escolares, tres de ellas se ubican dentro de la ciudad, la 114 al sur, y las 107 y 113 al norte. Y es la zona 107 quien inicia en la década de los ochenta la atención a la población indígena en la ciudad. ${ }^{26}$

El inicio de EI en la ciudad de Puebla data de 1986, cuando el supervisor Tito Mora se interesó por crear una zona escolar en la ciudad para atender a la población indígena nativa de La Resurrección, Canoa y la zona fronteriza con San Pablo del Monte, Tlaxcala, en donde algunos pobladores (sobre todo gente mayor) aún hablan náhuatl.

El profesor Mora se avocó a realizar los trámites para la apertura de esta zona escolar ante la SEP y comisionó a cuatro maestros para que inscribieran niños. Él justificó la apertura de las escuelas al señalar que estaban situadas en una zona hablante de náhuatl y presentando listas con los nombres de niñas y niños vecinos de esta zona a quienes se atenderían. Esto se facilitó, señala el director de la escuela Emiliano Zapata "porque los niveles educativos de preescolar y primaria general no estaban interesados en abrir escuelas en esos lugares carentes de todos los servicios". Recordemos que esos espacios periurbanos se estaban poblando, lugares que se consideraban rurales y reserva territorial, sin ninguna planeación urbana y carentes de permisos de construcción. La profesora Micaela Espíritu es una de los cuatro docentes que laboraron cuando inició la zona escolar y refiere al respecto:

manifestaciones más o menos intensas, y que mantienen en el horizonte como riesgo la acentuación, el entrampamiento en círculos de desventaja: la exclusión.

${ }^{26}$ Esta zona escolar posteriormente se divide, creándose la 113 con una cobertura al nororiente de la ciudad de Puebla y en los municipios de Amozoc, Tepatlaxco, Acatcingo y Tepeaca. En la zona escolar 113 se ubican las tres escuelas del estudio, en las colonias Nueva Resurrección y San Antonio Abad. 
Yo inscribí nińos en Cerritos, no conocíamos el lugar, solo nos dijo el profesor Tito que antes de llegar a San Pablo del Monte estaban las casas, nos perdimos porque hay barrancos, allí otros tres maestros y yo hicimos las inscripciones, pasamos casa por casa. Juntamos nińos para preescolar. Yo allí no me quedé porque el profesor Tito me mandó después para acá [Nueva Resurrección] a buscar más niños. Junté treinta niños para preescolar también juntamos para primaria, eso que ya estábamos en octubre. En septiembre no había nada, ni escuela, ni niños, pero el profesor Tito ya había hecho unas listas que entregó a la SEP según que de alumnos, cuando todavía no habíamos ido a buscarlos. Empezamos ahora sí, buscando niños y luego un local. Se puede decir que EI desde ese entonces ya estaba en la ciudad (Profra. Micaela Espíritu).

Se abrieron cuatro preescolares, todos multigrado, en Aparicio, Tres Cerritos, San Miguel Canoa y Nueva Resurrección. En esta última colonia también se abrió una primaria. La maestra Micaela señala que el Comisariado Ejidal se interesó por las escuelas (preescolar y primara) porque él hablaba náhuatl y además se necesitaban escuelas de preescolar y primaria para los nińos de esta colonia, que carecían de todo. Los estudiantes no hablaban náhuatl; sin embargo, asistían a ellas porque eran las únicas instituciones escolares.

En este caso, el comisariado ejidal advierte que las escuelas de EI eran, en esos momentos, la única opción para contar con el servicio educativo en dicha zona; además, también se identificaba con EI, como hablante del náhuatl, e incluso intervino directamente en la creación de estos centros educativos: "Julián y Nácer [Secretario de Educación en Puebla] le dijo al profesor Tito que no había indígenas en Puebla, por lo que no se justificaba esta modalidad educativa en la ciudad y el comisariado dijo ‘Cómo no!' Y le escribió al secretario una solicitud en náhuatl pidiendo la escuela para la Nueva Resurrección. El comisariado nos ayudó mucho porque se identificaba con nosotros" (Profra. Micaela Espíritu).

Con ello advertimos cómo se van conformando las relaciones interétnicas del espacio periurbano que articula la parte indígena náhuatl y mestiza del lugar, con la llegada de instituciones del Estado: las escuelas de EI (inicialmente con maestros indígenas nahuas, mixtecos y totonacos) y las familias pertenecientes a grupos 
indígenas y mestizos inmigrantes, confluyendo todos, de manera espontánea, para gestionar, sin ninguna planeación, los servicios mínimos en la colonia.

Las escuelas carecían de todo, lo más notorio fue la infraestructura $^{27}$ y el personal docente necesario; sin embargo, a partir de gestiones y el apoyo de los padres fueron creciendo y todas se convirtieron, con el tiempo, en centros de organización completa. El personal se conformó en un inicio sobre todo con profesores indígenas que ya se habían arraigado en la ciudad por trabajar en la SEP y el Sindicato Nacional de Trabajadores de la Educación (SNTE). Al tener la necesidad de regresar a la docencia, buscaron nichos laborales que les permitieran seguir viviendo en la ciudad. De esta manera, este sector fue creciendo y estableciendo escuelas en zonas periurbanas, la mayoría en asentamientos irregulares que no contaban con los servicios mínimos. Actualmente existen diez preescolares y diez primarias de EI en la ciudad de Puebla.

En esta dinámica y, contrario a los datos con los que se inicia EI en la ciudad de Puebla, las escuelas tanto preescolares como primarias de estas zonas, no atienden a niños hablantes nahuas oriundos de Tres Cerritos, Manzanilla, Canoa y Nueva Resurrección, sino en su mayoría a niñas y niños que llegaron a poblar junto con sus padres estos asentamientos y, en la actualidad, a la segunda y tercera generaciones radicados en el lugar. Dentro de esta población se encuentran hijos de familias migrantes indígenas y campesinas que llegaron de diversos lugares, especialmente familias indígenas de la Sierra Nororiental y la Mixteca poblana e incluso de los estados de Tlaxcala, Oaxaca y Veracruz.

Es posible identificar que en los tres centros escolares (en los que se sitúa el estudio) existe una diversidad étnica. Sin embargo, mayoritariamente, prevalecen los mestizos y alumnos que ya nacieron en la ciudad, de padres indígenas y campesinos (con diversidad de apropiación de una lengua indígena $-\mathrm{o}$ nula- $\mathrm{y}$

\footnotetext{
27 "Iniciaron sin nada, en un cuarto prestado; luego consiguieron un terreno, eso lo lograron los propios maestros. En el terreno que ya era de la escuela, los maestros se pusieron a construir unos cuartos para dar clase; si viera usted como los veíamos trabajar por su escuela, hasta daba lástima verlos como albañiles y es que la SEP no les ayudaba. Esta escuela [Fuertes de Guadalupe y Loreto] les costó a ellos y a nosotros como padres de familia. Ya luego, yendo de aquí para allá, conseguimos que se construyeran los edificios" (Padre de familia presidente del comité de obras para la construcción de la escuela Fuertes de Guadalupe y Loreto).
} 
con procesos de socialización urbanos); frente a los estudiantes inmigrantes indígenas y campesinos que, de manera reciente, se incorporan a estas escuelas con grandes dificultades. El cuadro uno nos muestra los porcentajes de estos últimos y su procedencia por escuela.

CUADRO 1. Estudiantes inmigrantes en tres escuelas de El

\begin{tabular}{|l|c|c|l|l|}
\hline \multicolumn{1}{|c|}{ Escuela } & $\begin{array}{c}\text { Matrícula escolar al } \\
\text { inicio del ciclo escolar } \\
2014-2015\end{array}$ & $\begin{array}{c}\text { Porcentaje de alumnos } \\
\text { migrantes campesinose } \\
\text { indígenas al inicio } \\
\text { del ciclo escolar }\end{array}$ & $\begin{array}{c}\text { Movilidad de } \\
\text { Origen étnico de los } \\
\text { estudiantes migrantes }\end{array}$ & $\begin{array}{l}\text { septiembre a febrero } \\
\text { (traslados y bajas de } \\
\text { estudiantes) }\end{array}$ \\
\hline $\begin{array}{l}\text { Fuertes de Gpe. } \\
\text { y Loreto, turno } \\
\text { matutino, } \\
\text { ubicada en la } \\
\text { colonia Nueva } \\
\text { Resurrección }\end{array}$ & 872 & $.36 \%$ & $\begin{array}{l}\text { Totonaco, náhuatl, } \\
\text { zapoteco mixteco y } \\
\text { mestizo }\end{array}$ & $\begin{array}{l}\text { Hubo solicitudes } \\
\text { de ingreso por } \\
\text { traslado pero fueron } \\
\text { rechazadas porque la } \\
\text { población estudiantil } \\
\text { es numerosa }\end{array}$ \\
\hline $\begin{array}{l}\text { Emiliano Zapata, } \\
\text { turno matutino, } \\
\text { ubicada en la } \\
\text { colonia San Antonio } \\
\text { Abad }\end{array}$ & 539 & $23.9 \%$ & $\begin{array}{l}\text { Totonaco, náhuatl, } \\
\text { zapoteco, mixteco y } \\
\text { mestizo }\end{array}$ & $\begin{array}{l}\text { 42 ingresos por } \\
\text { traslado y 10 bajas }\end{array}$ \\
\hline $\begin{array}{l}\text { Tierra y Libertad, } \\
\text { turno vespertino, } \\
\text { ubicada en la } \\
\text { colonia San Antonio } \\
\text { Abad }\end{array}$ & 442 & $13.5 \%$ & $\begin{array}{l}\text { Totonaco, náhuatl, } \\
\text { zapoteco, mixteco, } \\
\text { popoloca, ñähñu, } \\
\text { mazateco y mestizo }\end{array}$ & $\begin{array}{l}17 \text { ingresos por } \\
\text { traslado }\end{array}$ \\
\hline
\end{tabular}

Fuente. Elaboración propia a partir de datos recabados in situ.

Observamos, en el cuadro uno, que existe una diversidad en el origen étnico en las tres escuelas; sin embargo, en la de Fuertes de Guadalupe y Loreto se observa una disminución importante en la población migrante reciente. Los estudiantes son segunda y tercera generación ya establecida en la Nueva Resurrección, que dejó de hablar la lengua de sus abuelos; en cambio, las otras dos escuelas siguen recibiendo a población campesina e indígena en un porcentaje relativamente mayor. Destaca en ello la escuela Emiliano Zapata con $23.9 \%$. Además, encontramos durante la primera mitad del ciclo escolar, una alta movilidad. ${ }^{28} \mathrm{El}$ director de la escuela Emiliano Zapata refiere que "Los estudiantes llegan y se van

\footnotetext{
${ }^{28} \mathrm{La}$ SEP autoriza altas y bajas hasta el mes de mayo.
} 
todo el tiempo. Cuando no tienen trabajo sus padres se mueven y se llevan a la familia. Un niño asistió dos semanas y se fue".

Los recién inmigrados hablantes de alguna lengua indígena, son bilingües, pero con una apropiación básica del español, por lo cual se les dificulta acceder a los contenidos de los programas de estudio impartidos en español; además, la escolarización que tuvieron en sus lugares de origen fue precaria: "Los alumnos que están llegando, vienen con muchas deficiencias académicas. Apenas antier llegó un alumno para segundo año, le dije que leyera y nada. Vienen muy mal, así están todos" (Director Tierra y Libertad) (cfr. INEE, 2007).

Según datos del INEGI (2005), la condición étnica y el bajo nivel de escolarización son factores que dificultan los procesos migratorios; sin embargo, la población indígena está emigrando con mayor frecuencia, llevando las consecuencias de las desigualdades sociales que se tienden a reproducir en los lugares de arribo y en la trayectoria de movilidad: "yo tengo tres niños que llegaron del Distrito Federal y vienen muy mal. Bueno sí, son niños que migraron de sus pueblos hacia México y ahora se vinieron para acá" (Profr. Tierra y Libertad).

Las condiciones de pobreza en las que el sistema estatal mantiene a las poblaciones indígenas repercute de manera directa en lo educativo. Esto, al parecer, es una constante en América Latina: "la situación de pobreza, como es de suponer, guarda una especial relación con la particular situación educativa y con los rezagos educativos encontrados en áreas indígenas" (López, 2001: 5). El INEE confirma esto para el propio caso de México (2006, 2007, 2009), mientras que el Programa Sectorial de Educación 2013-2018 reconoce que:

Las acciones para una educación de calidad han sido desiguales e inequitativas. Las escuelas más pequeńas y alejadas, con poblaciones con mayor incidencia de pobreza y marginación, como en el caso de las comunidades indígenas, mantienen sistemáticamente los resultados más bajos” (SEP, 2013b: 30).

Esto explica el bajo rendimiento académico al que hace referencia el director de la Escuela Tierra y Libertad. Pero a ello 
se suma que en la ciudad de Puebla, los maestros generalmente reconocen a estos estudiantes como problema (según lo refieren tanto el director de la escuela Emiliano Zapata como la de Tierra y Libertad); además de que estos centros educativos carecen de un proyecto educativo pertinente centrado en procesos de interculturalidad abiertos.

La diversidad indígena que se genera por la llegada de niños migrantes a estas escuelas está integrada en aulas pluriculturales. Sin embargo, no existe un proyecto pedagógico que recupere la diversidad cultural e incluso los maestros no la reconocen: "Para los maestros son invisibles, no los toman en cuenta por sus diferencias culturales, solo se refieren a ellos porque señalan que tienen problemas de aprendizaje, pero no hay diagnóstico, solo los advierten como un problema" (Dir. Emiliano Zapata).

Esto se debe, en gran medida, a que en las tres escuelas se ha instituido "la visión indigenista de la interculturalidad: la interculturalidad para indígenas" (Dietz y Mateos, 2011: 161) aunque las escuelas se caracterizan por la presencia de estudiantes indígenas de más de una etnia y los mestizos son mayoría.

De esta manera, la interculturalidad que caracteriza a EI, en las tres escuelas, no es una práctica pedagógica que recupere las lenguas indígenas y contenidos étnicos de los estudiantes indígenas, y construya junto a la cultura de los niños mestizos procesos de aprendizaje y respeto multicultural. Más bien asumen únicamente un discurso idealizado de EI, el cual ha sido construido sobre las bases de la atención de población indígena en las regiones de origen y no para población migrante en las ciudades de arribo como es el caso que nos ocupa. ${ }^{29}$ Junto a ese discurso encontramos prácticas mínimas en que se emplea el náhuatl; pero ello no posibilita el aprendizaje básico de dicha lengua.

Respecto a la lengua materna de los estudiantes inmigrantes recientes y su nivel de bilingüismo encontramos que, debido a las históricas políticas de integración, estos estudiantes, a pesar

\footnotetext{
${ }^{29}$ Es de hacer notar que la propia SEP en diferentes documentos como, el Plan Sectorial de Educación (SEP, 2013b), el Plan de Estudios de Educación Primaria (SEP, 2011) y Marcos Curriculares (SEP, 2012, 2013a) hace referencia a los niños indígenas y población migrante pero por esta última, no se refiere a los migrantes de la ciudad, sino a los niños jornaleros agrícolas. De esta manera, los niños indígenas migrantes a las ciudades también son invisibles para la SEP.
} 
de hablar una lengua indígena, suelen negarlo y es solamente de manera accidental como los profesores llegan a percatarse de su bilingüismo, pero no es atendido ni recuperado de manera curricular en las aulas, provocando que exista un bajo aprovechamiento escolar en estos alumnos.

Hay aproximadamente sesenta nińos que hablan una lengua indígena, náhuatl, totonaca, popoloca y hay dos estudiantes mixtecos. Los hemos detectado pero, la verdad, los maestros no se enfocan en ellos porque no se dan abasto. Estamos tratando de ver qué hacer; la verdad no hay un diagnóstico pero en Consejo Técnico planteamos la necesidad de hacer un vocabulario en náhuatl, popoloca y totonaco, tenemos maestros que hablan esas lenguas, de los trece maestros dos son hablantes de náhuatl, dos de popoloca y uno de totonaco (Director Tierra y Libertad).

Por su parte, el maestro de Tierra y Libertad señala:

Tengo un alumno mixteco, yo no sé mixteco y él entiende el español, así es que todo lo enseño en español, estaría bien que tuviera tiempo para que él también lo que expresa en español, lo expresara en mixteco, para que no se le olvidara y sus compañeros escucharan otro idioma, pero no tenemos tiempo para eso. Cuando damos la clase de náhuatl le pregunto a él cómo se dice en mixteco (Profr. Tierra y Libertad).

Al revisar los formatos de inscripción de los alumnos por grado, identificamos que los maestros indican que los alumnos son hablantes del náhuatl como una manera de mostrar que es una escuela indígena que trabaja con estudiantes indígenas, incluso hasta evalúan a los estudiantes en la asignatura de lengua indígena, pero no realizan un diagnóstico para saber si sus alumnos hablan una lengua diferente al español y si esta es únicamente náhuatl, o el nivel de apropiación que tienen de ella y del español; para que pudiesen elaborar proyectos de enseñanza bilingüe que permitan que estos nińos aprendan a partir de sus necesidades comunicativas.

Además de la diversidad étnica de los alumnos, encontramos la diversidad étnica de los maestros. ${ }^{30} \mathrm{Y}$ aunque algunos saben una

\footnotetext{
${ }^{30}$ Que los profesores hablen una lengua indígena se debe a que uno de los requisitos para que la SEP contrate a los docentes de esta modalidad, es que sean hablantes de una lengua
} 
lengua indígena, en nuestras observaciones en las aulas identificamos que no están potenciando el bilingüismo de sus estudiantes.

Los datos que arrojan las tres escuelas son los siguientes: de los 45 maestros, 18 hablan una lengua indígena; es decir, solo $40 \%{ }^{31}$ En el cuadro dos podemos observar el porcentaje de ellos en cada una de estas instituciones educativas y la lengua que hablan. También aparece este rasgo en relación con el origen étnico de los alumnos.

CUADRO 2. Profesores hablantes de una lengua indígena

\begin{tabular}{|l|c|c|c|l|}
\hline \multicolumn{1}{|c|}{ Escuela } & $\begin{array}{c}\text { Número de } \\
\text { profesores }\end{array}$ & $\begin{array}{c}\text { \% de profesores } \\
\text { hablantes de una LI* }\end{array}$ & $\begin{array}{c}\text { Ll que hablan los } \\
\text { profesores indigenas }\end{array}$ & \multicolumn{1}{c|}{ Origen étnico de los alumnos } \\
\hline $\begin{array}{l}\text { Fuertes de Gpe. } \\
\text { y Loreto }\end{array}$ & 19 & $31 \%$ & Náhuatl y mixteco & $\begin{array}{l}\text { Totonaco, náhuatl, zapoteco, } \\
\text { mixteco y mestizo (de las cuatro } \\
\text { etnias indígenas detectadas en la } \\
\text { escuela, solo existen profesores que } \\
\text { hablan la lengua de dos de ellas). }\end{array}$ \\
\hline $\begin{array}{l}\text { Emiliano } \\
\text { Zapata }\end{array}$ & 14 & $50 \%$ & Náhuatl y popoloca & $\begin{array}{l}\text { Totonaco, náhuatl, zapoteco, } \\
\text { mixteco y mestizo. } \\
\text { De las cuatro etnias indígenas } \\
\text { detectadas en la escuela, solo } \\
\text { existen profesores que hablan la } \\
\text { lengua de una de ellas. }\end{array}$ \\
\hline $\begin{array}{l}\text { Tierra } \\
\text { y Libertad }\end{array}$ & 12 & $41 \%$ & $\begin{array}{l}\text { Totonaco, náhuatl, zapoteco, } \\
\text { mixteco, popoloca, ñähñu, } \\
\text { mazateco y mestizo. } \\
\text { De las siete etnias indígenas } \\
\text { detectadas en la escuela, solo } \\
\text { existen profesores que hablan la } \\
\text { lengua de tres de ellas. }\end{array}$ \\
\hline
\end{tabular}

Fuente. Elaboración propia a partir de las estadísticas de las escuelas y entrevistas a los directores.

*LI= Lengua Indígena

Como se observa en el cuadro dos, menos de la mitad de los maestros habla una lengua indígena, pero además, en ninguna de las tres escuelas los maestros hablan todas las lenguas indígenas del origen étnico de los alumnos. Además, por las observaciones realizadas y las entrevistas, nos dimos cuenta de que los maestros que hablan una lengua indígena diferente al náhuatl, enseñan el

indígena, sin embargo, los datos de las tres escuelas nos muestran que no todos cumplen con este requerimiento.

${ }^{31} 40 \%$ de los maestros habla una lengua indígena, pero detectamos cinco maestros más (cuatro de Fuertes de Guadalupe y Loreto y uno de Emiliano Zapata) que son hijos de maestros indígenas, quienes sí hablaban una lengua indígena. pero no se la enseñaron a sus hijos, que ahora son docentes en estas escuelas de EI. 
náhuatl como asignatura y solo en el caso que detecten que tienen algún alumno hablante de su propia lengua, hablan con él o ella en forma bilingüe, tratando de emplear la lengua indígena que saben en común, como vehículo de enseñanza de los contenidos del currículo, pero esto solo en el caso de que al estudiante se le dificulte comprender lo que les está explicando a todo el grupo en español.

Respecto a la enseñanza bilingüe, en las tres escuelas se enseña una hora semanal la lengua náhuatl, únicamente como asignatura. Esto, en principio, es insuficiente y además no todos los niños que llegan son hablantes de la lengua náhuatl (ni los maestros), pues como observamos en los cuadros uno y dos en esas tres escuelas hay estudiantes de origen étnico totonaco, popoloca, ñähñu, mazateco, mixteco y zapoteco y maestros nahuas, popolocas, mixtecos y totonacas. ${ }^{32}$

Con respecto a las actividades curriculares, advertimos que como materiales rectores del trabajo educativo se encuentran los planes y programas generales, y solo de manera colateral, se recuperan los parámetros curriculares de la asignatura de lengua indígena (SEP, 2005) diseñados para estudiantes de primaria hablantes de una lengua indígena; pero no existen prácticas plurilingües en el quehacer educativo con estos estudiantes.

Aquí trabajamos con todos los niños con el nuevo programa, también tratamos de trabajar con Parámetros Curriculares, pero no se puede bien porque los niños no hablan náhuatl, les enseñamos, pero el popoloca ¿Cómo le enseńamos? (Profr. Emiliano Zapata).

Por su parte el maestro de Nueva Resurrección señala:

A esta colonia antes llegaban niños que hablaban otras lenguas indígenas, ahora ya están naciendo aquí los niños. Raros son los que llegan, son pocos; entonces, no tenemos ese problema generalizado (Profr. Fuertes de Guadalupe y Loreto).

\footnotetext{
${ }^{32}$ Pero recordemos que la Jefatura de Supervisión es la 02 Región nahua (así identificada porque se ubica en asentamientos donde hubo población náhuatl y por ello se justificó que se diera la modalidad de EI) debido a ello, se enseña el náhuatl.
} 
En todos los casos, la lengua que media entre los maestros y los estudiantes es el español y no hemos encontrado prácticas interculturales y plurilingües desarrolladas a partir de una planeación de escuela y de grupo; de esta manera, se trabaja al "estilo de las escuelas generales", con la variante de cantar el himno nacional en náhuatl; las escoltas dan las órdenes en forma bilingüe, se incluyen ciertos señalamientos de seguridad e informativos en los muros escolares con textos bilingües (náhuatl-español); se tiene, como ya se mencionó, una asignatura de náhuatl, una hora a la semana, en la cual se enseñan los colores, los números, algunos sustantivos y frases (saludo, despedida, permiso para salir al baño, etc.) que tienden a repetirse durante los seis grados sin un proceso gradual de complejidad en la enseñanza según los grados escolares.

Las prácticas referidas no permiten que los estudiantes monolingües logren un aprendizaje básico de esta segunda lengua y las lenguas de los niños bilingües popolocas, mixtecos, ñähñus, mazatecos y zapotecos no se recuperan. Además, los nahuas tampoco usan su lengua dentro de la escuela, pues la asignatura que se da en náhuatl es muy elemental y no propicia un desarrollo oral ni escrito de dicha lengua.

Sin embargo, encontramos que en el discurso de las y los maestros, se ha acuñado la idea de que se debe mostrar hacia afuera la identidad indígena de la institución, sobre todo en eventos regionales. Su carta de presentación en esos eventos es el himno nacional en náhuatl que todas y todos los maestros y estudiantes, sin importar su origen étnico, saben porque cada lunes en las ceremonias cívicas es cantado por todos.

Por otro lado, advertimos en las relaciones con los padres de familia y los niños, que los profesores tienen cierto grado de identificación con las familias de sus estudiantes, debido a que ellos también son migrantes indígenas o rurales, pero ellos lograron ser docentes. ${ }^{33}$ Esto les permitió, no sin tensiones y contradicciones, cierto reconocimiento de su identidad indígena y entender las condiciones de vulnerabilidad de sus estudiantes ante los procesos de migración en condiciones de evidente exclusión social.

\footnotetext{
${ }^{33}$ Esto se puede explicar debido a que "dentro de la dinámica nacional de incorporación de los indígenas como intermediarios de las políticas estatales, el magisterio bilingüe fue el principal nicho de profesionalización de los indígenas" (Chávez, 2014: 232).
} 
Yo veo a los niños que vienen de los pueblos, les cuesta trabajo la escuela porque aquí es diferente. Las familias están muy pobres, se dedican a recolectar pet, de eso viven. Así es difícil. Yo lo sé. Yo me acerco a ellos, voy a sus casas. En lo que puedo les ayudo para que no dejen de venir a la escuela (Profr. Emiliano Zapata).

Además, algunos profesores (aproximadamente 60\%) viven en estas colonias ${ }^{34}$ formando parte de ese conglomerado pluriétnico. Con ello, de diversas formas comparten el espacio más allá de la escuela e interactúan con los otros desde su condición de migrante indígena asentado y su identificación como docente.

Lo anterior nos muestra las relaciones de los profesores con la población. Por otro lado, respecto a la institución escolar situada en este espacio periurbano; advertimos que las escuelas de EI son identificadas por los colonos y autoridades debido a que son atendidas por profesores indígenas; son consideradas escuelas pobres y allí se recibe a los niños rechazados de otras escuelas. De esta manera, el origen étnico de sus profesores y el reconocimiento como escuela para pobres parece el rasgo distintivo, sobre todo de las escuelas Emiliano Zapata y Tierra y Libertad. ${ }^{35}$

Más allá de la identidad indígena que tratan de crear las y los profesores y del reconocimiento de la comunidad; advertimos que estos centros escolares están recibiendo una población migrante, conformando un espacio áulico pluricultural, diverso y en tránsito, que se atiende de manera homogénea. En este sentido, es importante que en la escuela, en principio, se advierta esta heterogeneidad, se asuma la presencia de población flotante y se creen programas educativos que permitan el aprendizaje recuperando y potenciando la experiencia desde la movilidad y el encuentro.

Ante esta realidad, es necesario señalar de manera preponderante la relación que existe entre cultura y pobreza para pensar en propuestas de intervención educativa en un país caracterizado por la ya histórica desigualdad (Muñoz, 1996; Salinas 2013). Al

\footnotetext{
${ }^{34}$ Algunos rentan la vivienda que habitan y otros son propietarios.

${ }^{35}$ El caso de la escuela de Fuertes de Guadalupe y Loreto no es tan contundente debido a que, por mucho tiempo, fue la única institución educativa y fue recibiendo también a niños con mejores recursos económicos.
} 
respecto, Arizpe (2006) refiere que "frente a la injusticia cultural es necesario plantear una política de reconocimiento sumada a una política de la redistribución." (Confr. López Nestor et al., 2012 y Fachelli et al., 2012). De lo contrario, las tendencias globalizadoras que señala Bauman (2006) seguirán segregando aún más a la población indígena migrante.

$\mathrm{Y}$ es que, a pesar de existir documentos como la Declaración Universal de los Derechos del Niño (ONU,1959), la Convención relativa a la lucha contra la discriminación en la esfera de la enseñanza (UNESCO,1960), la Convención sobre los Derechos del niño (UNESCO, 1989), la Declaración Universal de los Derechos Lingüísticos (UNESCO, 1996), ratificados por México y, a nivel nacional, el artículo cuarto constitucional (Cámara de Diputados del H. Congreso de la Unión, 2012a), la Ley General de Derechos Lingüísticos de los Pueblos Indígenas (Cámara de Diputados del H. Congreso de la Unión, 2012b) y la reciente Ley General de los Derechos de las Niñas, Niños y Adolescentes en México (Cámara de Diputados del H. Congreso de la Unión, 2014); los estudiantes indígenas migrantes parecen ser el eslabón más frágil y vulnerado de la sociedad mexicana (cfr. INEE, 2007), a quienes se les niega toda su identidad étnica dentro y fuera de los salones de clase.

En este sentido, desde el DE advertimos, primero, que estas y estos estudiantes cargan con una herencia de exclusión educativa $y$, por otro lado, en los lugares de origen y a donde migran, se les integra a toda costa a los parámetros educativos generales sin advertir su diversidad lingüística y cultural. Estas y estos niños están lejos de que el DE que refiere Latapí (2009) sea clave para acceder a los demás derechos humanos.

Respecto a la lengua de enseñanza, Tomasevski (2002), señala que:

La transmisión intergeneracional a través de la escolarización institucionalizada es vital para la supervivencia de cualquier cultura. Sin embargo la educación como derecho cultural se ha visto abrumada por las dimensiones políticas de la elección de los idiomas oficiales y de los idiomas de instrucción, sus repercusiones financieras y las distintas experiencias en 
cuanto a la promoción de los mejores intereses de los educandos (Tomasevski, 2002: 11).

En este estudio sobresale que, si bien las lenguas indígenas son lenguas oficiales en nuestro país y está estipulada la enseñanza de estas en la escuela, así como el reconocimiento a las culturas indígenas, las experiencias que presentamos muestran que estos centros educativos no tienen la capacidad de atender con pertinencia (de forma bilingüe e intercultural) a los estudiantes indígenas migrantes, pues no se trabaja a partir de los mejores intereses de los educandos, lo que fomenta la exclusión educativa.

También es necesario mostrar que, a pesar de la supuesta superación de exclusiones (segregación e integración) por las que ha transitado el DE (Tomasevski, 2002), en EI encontramos que, por las condiciones en que se han creado y funcionan las escuelas en la ciudad, estas instituciones son espacios de segregación debido a que se han caracterizado porque a ellas asisten las y los niños más vulnerados de esas colonias, de por sí marginadas. De esa manera, se ha desplazado lo étnico a la condición de pobreza; es decir, de manera natural, los niños migrantes indígenas y campesinos llegan a esas escuelas segregadas.

Este tipo de segregación tiene que ver, de acuerdo con López Néstor, con "La relación Estado-sociedad, la cual constituye un vínculo de poder sumamente asimétrico, que se despliega de un modo arrasador en el tratamiento de la diversidad, donde se ponen en evidencia muchas de las prácticas a través de las cuales se generan las formas cotidianas de discriminación” (2012: 27).

De manera paradójica, estas escuelas también operan como espacios de integración. Esto lo advertimos en su funcionamiento. $\mathrm{Y}$ es que las y los profesores tienen como eje rector los planes y programas generales y no logran vincularlos con propuestas interculturales donde se potencie la diversidad lingüística y étnica.

\section{CONSIDERACIONES FINALES}

Las escuelas de EI en la ciudad de Puebla, desde su creación, han tenido como fundamento, los mismos postulados indigenistas que tienen las instituciones educativas indígenas en las regiones 
originarias de estas poblaciones, a pesar de que este planteamiento ha sido cuestionado y rebasado por las mismas comunidades indígenas que luchan por su reivindicación. Además, la población a la que atienden se distingue por una diversidad étnica (indígenas y mestiza) producto de la migración.

En las condiciones en que se aperturan y operan las escuelas de EI en la ciudad de Puebla, estas se convierten en espacios de segregación, pues asisten a estos centros educativos los estudiantes más vulnerados, articulándose a la identidad étnica.

También encontramos que, en estas escuelas, la población mayoritaria es mestiza; de esta manera, los inmigrantes indígenas y campesinos son minoría y las prácticas escolares tienden de manera implícita y explícita a integrarlos a los modelos educativos generales, sin una propuesta pedagógica que atienda sus necesidades y formas de aprendizaje. Lo anterior nos muestra que, tanto la segregación como la integración, están presentes en el día a día de estas escuelas a pesar de que desde el DE se trata de superar estas formas de exclusión.

En sintonía con el cosmopolitismo (que parte de los principios de la ilustración y la modernidad $\left.{ }^{36}\right)$, el ya histórico proyecto pedagógico de intervención que tiene como tesis cultural ordenadora, la razón, la ciencia y la libertad (Popkewitz, 2009), mantiene sedimentos nodales en la escolarización actual. En este tenor, las escuelas indígenas de la ciudad, al construir "sujetos razonables", excluyen a los sujetos más alejados de la razón acuñada en occidente; en este sentido, los estudiantes migrantes indígenas que llegan a ella (como minorías que no se ajustan a dichos parámetros) son excluidos del proyecto educativo.

Por supuesto, los docentes de estas escuelas no vinculan la diversidad cultural y lo pedagógico en sus prácticas áulicas, ya que invisibilizan el bagaje étnico de los estudiantes migrantes indígenas imponiéndoles la cultura dominante como única cultura de transmisión de legado social; por otro lado, reconocen que estos recién llegados tienen bajos logros educativos, producto -refieren- de la formación deficiente que tuvieron en sus comunidades de origen.

\footnotetext{
${ }^{36}$ Kant presenta al líder ilustrado como el tutor que enseña que el deber de todo ciudadano es pensar por sí mismo. El tutor encarnaba el intento doble de ordenar y administrar el mundo por medio de la razón (Popkewitz, 2009: 29).
} 
EDUCACIÓN INDÍGENA EN LA CIUDAD: RECUENTO DE MIGRACIONES, ASENTAMIENTOS Y...

Sin reconocer que ellos tampoco tienen prácticas pedagógicas pertinentes al pasar por alto las necesidades educativas de sus estudiantes (como el bi-plurilingüismo y el aprendizaje de saberes en más de una cultura).

Si bien EI cuenta con infraestructura y personal docente que atiende a la población indígena y campesina migrante que llega a la ciudad de Puebla, tanto en las comunidades indígenas como en las ciudades de inmigración, no existe un proyecto puntual que recupere la experiencia migratoria como posibilidad de aprendizaje y debate, articulando puntos de salida con puntos de retorno y encuentro.

Las escuelas de EI en la ciudad, de forma espontánea, se articulan a los procesos sociales de las colonias en que están situadas; de esta manera se crea un acercamiento importante entre el quehacer escolar y las actividades comunitarias. Desde este vínculo social, la escuela debiera construir un vínculo educativo que responda a las necesidades educativas de esta localidad.

En estas escuelas se ha conformado una identidad étnica idealizada por los profesores, quienes tienen como un rasgo característico haber sido migrantes; sin embargo, estos, más que reafirmar y potenciar lo indígena desde un proyecto educativo viable, abanderan lo indígena como una forma de justificar la presencia de esta modalidad educativa en la ciudad.

Una vez planteado lo anterior, queda una pregunta: ‘ es posible diseñar formas de educación indígena en la ciudad, articuladas al proyecto educativo nacional sin ser experiencias marginales y empobrecidas? Creemos que no solo es posible, sino necesario asumir este reto como un compromiso de justicia social.

\section{REFERENCIAS BIBLIOGRÁFICAS}

Arias, Patricia. "Hacia el espacio rural urbano; una revisión de la relación entre el campo y la ciudad en la antropología social mexicana” en Estudios demográficos y urbanos, vol.17, núm.2, mayo-agosto, El Colegio de México, 2002.

Arias, Patricia. "Nueva ruralidad: antropólogos y geógrafos frente al campo hoy" en Ávila Sánchez Héctor (coord.), Lo 
urbano-rural, ¿nuevas expresiones territoriales? Cuernavaca, UNAM/CRI M, 2005.

Arizpe, Lourdes. Culturas en movimiento. Interactividad culturaly procesos globales, México, CRIM/UNAM/Miguel Ángel Porrúa, 2006.

Arizpe, Lourdes. Migración, etnicismo y cambio económico, México, El Colegio de México, 1978.

Ávila, Sánchez Héctor (coord.) Lo urbano-rural, ¿nuevas expresiones territoriales?, Cuernavaca, UNAM/CRI M, 2005.

Barth, Fredrk. Los grupos étnicos y sus fronteras. La organización social de las diferencias culturales, México, FCE, 1976.

Bartolomé, Miguel Alberto. "Fronteras estatales y fronteras étnicas en América Latina. Notas sobre el espacio, a temporalidad y el pensamiento de la diferencia", en Laura Velasco Ortiz (coord.) Migración, fronteras e identidades étnicas transnacionales, México, El Colegio de la Frontera Nortel Miguel Ángel Porrúa, 2008.

Bartolomé, Miguel Alberto. Gente de costumbre y gente de razón. Las identidades étnicas en México, México, Siglo XXI, 2004.

Bassols, Batalla Ángel. México, formación de regiones económicas, México, UNAM, 1979.

Bauman Zygmunt. La globalización. Consecuencias humanas, México, FCE, 2006.

Bello, Olano María de los Ángeles. Los conocimientos débiles. Multiculturalismo y cultura experencial en Barranca Honda, Tesis de maestría, Puebla, Posgrado/Universidad Pedagógica Nacional Unidad 211, 2004.

Bertely, Busquets María. "Conversatorio conocimiento y prácticas locales: conflictos y/o articulaciones", en $2^{\circ}$ Congreso Internacional Formando en Educación Intercultural. Retos y desafíos del siglo XXI, Oaxaca, REDFEIAL, 2015.

Bertely, Busquets María. Educación Indígena del siglo XX en México", en Pablo Latapí Sarre (coord.), Un siglo de educación en México II, México, CNCA/FCE, 1998.

Bhabha, Homi K. El lugar de la cultura, Buenos Aires, Manantial, 2002.

Calderón Cisneros Araceli y Lorena Soto Pinto. "Transformaciones agrícolas en el contexto periurbano de la ciudad de 
EDUCACIÓN INDÍGENA EN LA CIUDAD: RECUENTO DE MIGRACIONES, ASENTAMIENTOS Y...

San Cristóbal de las Casas Chiapas”, en Lima R. Estudios Sociales y Humanidades, México, Centro de Estudios Superiores de México y Centroamérica, vol. XII, núm. 1, enero-junio, 2014.

Cámara de Diputados del Honorable Congreso de la Unión (2012a), Constitución Política de los Estados Unidos Mexicanos, México: Cámara de Diputados del Honorable Congreso de la Unión.

Cámara de Diputados del Honorable Congreso de la Unión. Ley General de Derechos Lingüísticos de los Pueblos Indígenas, en Diario Oficial de la Federación, México, 2012b.

Cámara de Diputados del Honorable Congreso de la Unión. Ley General de las Niñas, Niños y Adolescentes en México, México, Cámara de Diputados del Honorable Congreso de la Unión, 2014.

Castoriadis, Cornelius. La institución imaginaria de la sociedad, Barcelona, Tusquets, 1989.

Chávez, González Mónica. Identidad étnica, migración y socialización urbana. Profesionistas indígenas de la Huasteca en la capital potosina, México, CIESAS/ El Colegio de San Luis, 2014.

D’Aubeterre María Eugenia y María Leticia Rivermar. "El ciclo histórico de las migraciones en el municipio de Pahuatlán, Puebla, en Estudios sociales, nueva época, núm. 4, 2008.

D’Aubeterre María Eugenia y María Leticia Rivermar. "From amate paper marking to global work: Otomí migration from Puebla to North Carolina", en Latin American Perspectives, vol. XX, núm. 30, 2014.

De Grammont, Hubert C. "Prólogo" en Ávila Sánchez Héctor (coord.) Lo urbano-rural, ¿nuevas expresiones territoriales? Cuernavaca, UNAM/CRIM, 2005.

Di Pierro, María Clara. "Notas sobre la trayectoria reciente de la educación de personas jóvenes y adultas en Latinoamérica y el Caribe", en Caruso, Arles et al., Situación presente de la educación de adultos en América Latina y el Caribe, Pátzcuaro, CREFAL, 2008.

Dietz Gunther y Laura Mateos. Interculturalidad y educación intercultural en México. Un análisis de los discursos nacionales 
e internacionales en su impacto en los modelos educativos mexicanos, México, SEP/CGEIB, 2011.

Dubar, Claude. La crisis de las identidades, Barcelona, Belaterra, 2002.

Fachelli, Sandra et al. Desigualdad y diversidad en América Latina: Hacia un análisis tipológico comparado, Buenos Aires, IIPE/UNESCO/SITEAL, 2012.

Franco, García Martha. "Educación Indígena en la ciudad. Un recuento contextualizado" en Tlakati. Revista de estudios sobre diversidad cultural, lingüistica y educativa, vol. I núm. 1, Puebla, UPN-211, 2013.

Giménez Montiel, Gilberto. Estudios sobre la cultura y las identidades sociales, México, CNCA/ITESO, 2007.

Gómez Calderón, Hilaria et al. "Relaciones de género en procesos migratorios periurbanos en Puebla, en Ra Ximhai, septiembre-diciembre, año/vol. 3, núm. 003, Universidad Autónoma Indígena de México, 2007.

INAFED. Enciclopedia de los municipios y delegaciones de México, Estado de Puebla. Disponible en http://wwwinafed.gob.mx/work/enciclopedia/EMM21puebla/ municipios/21114a:htm/ Fecha de consulta, 2 de enero de 2015.

INEE. El derecho a la educación en México. Informe 2009, México, INEE, 2009.

INEE. La calidad de la educación básica ayer, hoy y mañana. Conclusiones del informe anual sobre la calidad de la educación básica en México, 2006, México/INEE, 2006.

INEE. La educación para poblaciones en contextos vulnerables. Informe anual, 2007, México, INEE, 2007.

INEGI. Instituto de Geografía y Estadística. Aguascalientes, INEGI. Disponible en www.inegi.org.mx. Fecha de consulta, 7 de abril de 2012 .

INEGI. México en cifras. Información nacional por entidad federativa municipios, Aguascalientes, INEGI, 2010. Disponible en http://www3.inegi.org.mx/sistemas/mexicocifras/default.aspx?e=21. Fecha de consulta, 7 de mayo de 2012.

INEGI. Migración en Puebla, 2005, INEGI, Aguascalientes, 2005. 
EDUCACIÓN INDÍGENA EN LA CIUDAD: RECUENTO DE MIGRACIONES, ASENTAMIENTOS Y...

Krotz, Esteban. "Otredades, alteridad, diálogo intercultural: Aportes desde la antropología”, en $2^{\circ}$ Congreso Internacional Formando en Educación Intercultural. Retos y desafios del siglo XXI, Oaxaca, REDFEIAL, 2015.

Latapí, Sarre Pablo. "El Derecho a la Educación. Su alcance, exigibilidad y relevancia para la política educativa", en Revista Mexicana de Investigación Educativa, enero-marzo, vol. 14 núm, 40, 2009.

Lazarín, Federico. "La educación para las ciudades. Las políticas educativas 1940-1982", en Revista Mexicana de Investigación Educativa, México, enero-junio, vol. 1, núm. 1. 1996.

López, Luis Enrique. La cuestión de la interculturalidad y la educación latinoamericana, Chile, UNESCO/PROMEDLAC VII, 2001.

López, Marcos Eustacio. "Procesos de inserción y formación de docentes indígenas en dos licenciaturas de la UPN", en Patricia Medina Melgarejo (coord.), Voces emergentes de la docencia. Horizontes, trayectorias y formación profesional, México, Miguel Ángel Porrúa, 2005.

López Néstor et al. Equidad educativa y diversidad cultural en América Latina, París, UNESCO, 2012.

Mardones, José María. Filosofía de las ciencias humanas y sociales. Materiales para una fundamentación cientifica, Barcelona, Fontamara, 1983.

Martínez Buenabad, Elizabeth. "Vacíos en la práctica docente en aulas urbanas. Reflexiones desde una escuela primaria plurilingüe y multicultural de la Angelópolis como resultado de los procesos migratorios indígenas", Manuscrito, en XII Simposio Interamericano de Investigación Etnográfica en Educación, Mérida, CIESAS/UADY, 2008.

Muñoz Izquierdo, Carlos. Origen y consecuencias de las desigualdades educativas, México, FCE, 1996.

Olvera Rosas, Xochitl (dir. académica). "Marco Curricular de la Educación Primaria Indígena y de la Población Migrante", en La migración contemporánea en México, Fascículo II, México, SEP, 2013. 
ONU. Declaración Universal de los Derechos del Niño, OAS, 1959. Disponible en http://www.oas.org/dil/esp/Declaraci\%C3 $\% 83$ n\%2. Fecha de consulta, 13 de febrero de 2013.

Ornelas, Carlos. El sistema educativo mexicano. La transición de fin de siglo, México, FCE, 1995.

Patińo, E. "Periferia poblana: La desigualdad del crecimiento", en Papeles de Población, núm. 42, Universidad Autónoma del Estado de México, 2004.

Pérez Sánchez, Carmen Nieves. "La escuela frente a las desigualdades sociales. Apuntes sociológicos sobre el pensamiento docente", en Revista Iberoamericana de Educación, mayoagosto, núm. 23, Organización de Estados Iberoamericanos para la Educación, la Ciencia y la Cultura, 2000.

Piña, J. "Consideraciones sobre la etnografía educativa", en Perfiles Educativos, núm. 78, México, UNAM, 1998.

Popkewitz, Thomas S. El cosmopolitismo y la era de la reforma escolar, Madrid, Morata, 2009.

Portillo Hernández, Marisol. "La influencia del capital cultural de los profesores en su práctica docente. Estudio de caso en la escuela secundaria 14, Octavio Paz". Manuscrito, proyecto de investigación-maestría, Puebla, Posgrado/ Universidad Pedagógica Nacional, Unidad, 211, s/f.

Rello Fernando y Fernando Saavedra. "La problemática rural en México en perspectiva histórica: un marco de referencia para el análisis regional, en Saavedra Fernando y Fernando Rello (coords.) Integración y exclusión de los productores agrícolas. Un enfoque regional, México, FLACSO, 2012.

Rivermar, Leticia. Etnicidad y migración internacional. El caso de una comunidad nahua en el estado de Puebla, Puebla, BUAP, 2008.

Salinas Amescua, Bertha. "Introducción”, en Salinas Amescua Bertha (coord.) Educación, desigualdad y alternativas de inclusión, 2002-2011, México, ANUIES/COMIE, 2013.

Saraví, Gonzalo A. Transiciones vulnerables. Juventud, desigualdad y exclusión en México, México, CIESAS, 2009.

Schutz, Alfred y Thomas Luckmann. Las estructuras del mundo de la vida, Buenos Aires, Amorrortu, 2009. 
EDUCACIÓN INDÍGENA EN LA CIUDAD: RECUENTO DE MIGRACIONES, ASENTAMIENTOS Y...

SEP. "Marco Curricular de la Educación Primaria Indígena y de la Población Migrante", en La Migración contemporánea en México, Fascículo II, México, SEP, 2013a.

SEP. Marcos Curriculares de la Educación Primaria Indigena y de la población migrante. Fundamentación Normativa e Historia de la educación Primaria Indigena, México, SEP, 2012.

SEP. Parámetros curriculares de la asignatura de lengua indigena, México, SEP, 2005.

SEP. Plan de Estudios 2011. Educación Básica, México, SEP, 2011. SEP. Programa sectorial de educación 2013-2018, México, SEP, 2013b.

Taylor, S. J. y Bogdan R. Introducción a los métodos cualitativos de investigación, Buenos Aires, Paidós, 1990.

Tomasevski, Katarina. "Contenido y vigencia del derecho a la educación”, en Revista IIDH, vol. 36, 2002. Disponible en http://iidh-webserver.iidh.ed.cr/multic/UserFiles/Bi.

Touraine, Alain. ¿Podremos vivir juntos?, México, FCE, 1997.

UNESCO. Conferencia Mundial sobre Educación para Todos. Satisfacción de las Necesidades Básicas de Aprendizaje, Jomtien Tailandia, 1990, París, UNESCO, 1994.

UNESCO. Convención relativa a la lucha contra la discriminación en la esfera de la enseñanza, París, UNESCO, 1960.

UNESCO. Declaración Universal de los Derechos Lingüisticos, Barcelona, UNESCO, 1996.

UNESCO. Declaración Universal sobre la Diversidad Cultural, Lima, UNESCO, 2004.

UNESCO. Marco de Acción de Dakar. Educación para todos: cumplir nuestros compromisos comunes. Foro mundial sobre educación, Dakar, Senegal, 2000, París, UNESCO, 2000.

UNICEF. Convención Sobre los Derechos del Niño, Nueva York, ONU, 1989.

Vasilachis de Gialdino, Irene. "La investigación cualitativa”, en Irene Vasilachis de Gialdino (coord.), Estrategias de investigación cualitativa, Barcelona, Gedisa, 2006.

Von Groll Maren, Ulrike Keyser Ohort y Elías Silva Castellón. "Formación de Maestros indígenas y no indígenas para la educación indígena e intercultural”, en María Bertely Busquets, Gunther Dietz y María Guadalupe Díaz Tepe- 
REVISTA LATINOAMERICANA DE ESTUDIOS EDUCATIVOS, VOL. XLVI, NÚM. 4, 2016

pa (coords.), Multiculturalismo y educación, 2002-2011, México, ANUIES/COMIE, 2013.

Woods, Peter. Investigar el arte de la enseñanza. El uso de la etnografía en educación, Barcelona, Paidós, 1998.

Yonker, M. y Sylvia Schmelkes. Análisis de la implementación de las politicas interculturales bilingües en México. Informe presentado al Banco Mundial y a la Coordinación de Educación Intercultural Bilingüe, México, SEP, 2005. 